\title{
НЕКОТОРЫЕ АСПЕКТЫ ПРОДВИЖЕНИЯ ОНЛАЙН-ОБУЧЕНИЯ КАК МЕХАНИЗМА ЭКСПОРТА РОССИЙСКОГО ОБРАЗОВАНИЯ
}

\author{
(c) 2021 Забайкалов Андрей Павлович \\ кандидат юридических наук, доцент, доцент кафедры прикладного права \\ МИРЭА - Российский технологический университет, Россия, Москва \\ E-mail: zabaykalov@mail.ru
}

В статье рассмотрены некоторые аспекты применения дистанционного обучения с применением современных информационно-коммуникационных технологий. Отмечается, что в условиях противодействия новой коронавирусной инфекции онлайн-обучение выступает одним из основных направлений экспорта российского образования. При этом отечественные образовательные учреждения имеют компетенции, необходимые для его эффективного внедрения и применения. Предложены меры по продвижению экспорта российского онлайн-образования. Результаты исследования могут быть использованы в практической деятельности по экспорту образования, а также для совершенствования нормативного и организационного обеспечения такой деятельности.

Ключевые слова: академическая мобильность, виртуальная мобильность, виртуальный кампус, дистанционное обучение, дистанционные образовательные технологии, зарубежный учебный центр, новая коронавирусная инфекция, образовательная платформа, онлайн - обучение, открытое образование, Россотрудничество, экспорт образования.

В 2019 году, когда под эгидой ЮНЕСКО была принята Глобальная конвенция о признании квалификаций высшего образования, подчеркивалась инновационность норм о признании трансграничного образования и нетрадиционных способов обучения, в том числе, онлайнобучения и смешанного обучения [10]. Однако на тот момент отечественное законодательство уже продолжительное время содержало положения, позволявшие широко применять электронное обучение и дистанционные образовательные технологии при реализации образовательных программ. Такое право образовательных учреждений закреплялось, в частности, в части 2 статьи 16 Федерального закона от 29 декабря 2012 года № 273-Ф3 «Об образовании в Российской Федерации» [8]. Действующий порядок применения электронного обучения и дистанционных образовательных технологий был утвержден приказом Министерства образования и науки Российской Федерации от 23 августа 2017 г. № 816 [6].

Действие ограничительных мер, введенных и вводимых в связи с распространением новой коронавирусной инфекции, проявилось, в том числе, в повсеместном применении в ходе процесса образования на всех уровнях онлайнформата. Причем такое решение было принято не только в Российской Федерации, но и во многих зарубежных странах.

Онлайн-обучение в сложившихся условиях позволяет обеспечить реализацию права на образование, поскольку создает возможность, хотя и с трудностями и недостатками, но продолжить образовательный процесс. Альтернативой выступает приостановление работы образовательных учреждений на неопределенный период, перенос сессий и аттестационных мероприятий. Другой альтернативой является возврат к традиционной форме обучения на фоне прямой угрозы жизни и здоровья обучающихся, которую крайне сложно предотвратить.

Широкое использование электронных дистанционных образовательных технологий, которое наблюдается в настоящее время, как отмечает Министерство науки и высшего образования Российской Федерации, «неизбежно и осуществляется в целях повышения уровня эпидемиологической безопасности, в интересах сохранения здоровья студентов и преподавателей» [3]. При этом властям регионального и муниципального уровня, а также администрациям образовательных учреждений во многих случаях предоставлены полномочия решать вопрос о переходе на онлайн-обучение с учетом конкретных обстоятельств. Среди специалистов само по

* Исследование выполнено при финансовой поддержке РФФИ в рамках научного проекта № 19-011-00959. 
себе применение электронных дистанционных образовательных технологий в обычной образовательной деятельности не вызывает существенных вопросов, сомнений и возражений при условии его «альтернативности и дополнительности» [6, с. 107].

При этом опыт работы образовательных учреждений в период пандемии показал, что в целом отечественная система образования смогла продолжить свое функционирование в новых условиях. Подавляющее большинство обучающихся, с одной стороны, и педагогических работников, и образовательных учреждений, с другой стороны, смогли организовать необходимое взаимодействие. При этом исключения, как правило, были связаны с техническими вопросами: низкое качество или отсутствие связи, перегрузка серверов, отсутствие компьютеров и иных аналогичных устройств и т.д.

В любом случае, широкое применение дистанционных образовательных технологий, которые в настоящее время в большинстве случаев опираются на информационнокоммуникационные технологии, повышает доступность образования [4, с.48]. А это, среди прочего, может содействовать развитию экспорта российского образования. Это понимают многие государства, заинтересованные в сохранении или расширении своего присутствия на мировом рынке образовательных услуг, которые активно вкладывают ресурсы в поддержку онлайн-обучения [12; 14].

Представляется, что Российской Федерации не следует отставать в данном направлении. С одной стороны, в условиях ограничения передвижения обучающихся и снижения их мобильности одним из ключевых критериев выбора места получения образования за границей становится цена. А по данному показателю наша страна имеет конкурентные преимущества. С другой стороны, нельзя не отметить отмеченную наработку опыта в сфере онлайн-обучения, апробирование новых технологий и практик, хотя и во многом вынужденные.

Конечно, основная инициатива, должна исходить от образовательных организаций и, прежде всего, от высших учебных заведений. Причем более эффективным может стать их совместная деятельность в рамках различных форм партнерства, в том числе, с участием коммерческих предприятий, научных организаций и иных заинтересованных субъектов [9, с. 41-42].
В связи с этим можно предложить следующие дополнительные меры по продвижению экспорта российского онлайн-обучения.

Для части обучающихся, особенно из социально незащищенных слоев населения, критически влиять на доступность и качество дистанционного обучения могут материальнотехнические проблемы: отсутствие компьютерной техники, низкое качество связи, отсутствие места для выполнения заданий и т.д. Путь полноценного решения данной проблемы видится в повышении общего уровня жизни населения и развития инфраструктуры. Но это, к сожалению, в целом не быстрый процесс, особенно в условиях мирового экономического кризиса.

Вариантом обеспечения материальнотехнической возможности образования для иностранных граждан выступает создание зарубежных учебных центров. Такой центр позволяет иностранным студентам на территории государства своего гражданства или жительства пользоваться инфраструктурой, необходимой, прежде всего, для обучения, а также для консультаций, собеседований, общения и т.д. В некоторых случаях зарубежный учебный центр предоставляет даже возможность проживания. Практика создания таких центров реализована, в частности, вузами Австралии и Новой Зеландии в азиатских государствах [13].

Расположенные во многих странах мира Российские центры науки и культуры, а также иные представительства Федерального агентство по делам Содружества Независимых Государств, соотечественников, проживающих за рубежом, и по международному гуманитарному сотрудничеству (Россотрудничества) [7] могут в будущем выполнять аналогичные функции. Однако для этого следует несколько изменить концепцию деятельности таких центров, расширив их доступность и открытость. В настоящее же время Россотрудничество и его представительства хотя и задействованы в экспорте российского образования, но эпизодически. На их базе, как правило, проводятся отдельные мероприятия, направленные на привлечение иностранных студентов и помощь им в процессе получения образования в Российской Федерации: образовательные выставки, «дни открытых дверей», приемные кампании и т.д. [2].

Не утрачивает актуальности концепция «виртуальных кампусов», способных обеспечить дистанционное взаимодействие образова- 
тельных учреждений и обучающихся по организационным, техническим и иным вопросам. Более того, Европейская комиссия предложила внедрение данного инструмента в европейских университетах в рамках Плана действий по развитию цифрового образования на 2021-2027 годы [11]. Российские образовательные учреждения в целом не отстают в процессе такого внедрения, однако традиционно острой остается языковая проблема. Соответствующие системы в большинстве случаев поддерживают взаимодействие только на русским языке, что объективно не повышает привлекательность для иностранных обучающихся.

При этом следует помнить, что образование - это не только процесс получения знаний, но процесс развития личности. Поэтому наряду с «виртуальной мобильностью» студентов, которая предполагает возможность обучения с помощью информационно-коммуникационных технологий, а также общения по организационным вопросам, следует развивать практику взаимодействия студентов между собой, а также с преподавателями и иными лицами, задействованными в реализации учебной программы, вне рамок собственного образовательного процесса. По сути, речь идет о целесообразности, по возможности, переноса в виртуальное пространство всех аспектов студенческой жизни: праздников, творческих мероприятий, совместной работы и т.д.

Наконец, к мероприятиям, направленным на развитие дистанционного обучения, включая привлечение иностранных студентов, можно отнести создание специальных платформ для выбора и прохождения в онлайн-режиме образовательных программ и курсов. Особенно привлекательными являются платформы, позволяющие получить официальный диплом об образовании, в том числе, в результате прохождения совокупности краткосрочных курсов, а также зачесть пройденные курсы в различных образовательных учреждениях.

Попытка создания подобной платформы в Российской Федерации предпринята, например, в рамках проекта «Национальная платформа открытого образования» [5]. Представляется, что для ее более успешного развития следует расширить спектр языков, на которых ведутся курсы, причем не только за счет наиболее распространённых языков (английского, испанского, китайского, немецкого, французского и т.д.), но и с учетом перспективных для российского образования рынков.

Таким образом, онлайн-обучение в современных реалиях выступает перспективным направлением экспорта образования. При этом в условиях пандемии новой коронавирусной инфекции отечественные образовательные учреждения массового и во многом вынужденно приобрели компетенции, необходимые для эффективного внедрения и применения современных информационно-коммуникационных дистанционных образовательных технологий. Подобную ситуацию следует использовать максимально эффективно. Среди мер по продвижению экспорта российского онлайн-образования можно отметить такие как: создание сети зарубежных учебных центров, в том числе, на базе представительств Россотрудничества; внедрение многоязыковых «виртуальных кампусов»; поддержка внеучебной студенческой жизни иностранных обучающихся; развитие платформ для выбора и прохождения в онлайн-режиме образовательных программ и курсов с возможность официального признания (зачета) полученных знаний и навыков.

\section{Библиографический список}

1. Бунина С.Г. Четвертое поколение прав человека: онлайн-образование и доступ к Интернету // Современное право. 2020. № 8. 107.

2. Забайкалов А. П. Некоторые аспекты участия Россотрудничества в экспорте российского образования // Вопросы экономики и права. 2020. № 150. - С. 11-15.

3. Методические рекомендации Министерства науки и высшего образования Российской от 18 марта 2020 г. «Экспертные разъяснения по вопросам, возникающим в связи с использованием онлайн-курсов в целях предупреждения распространения коронавирусной инфекции». - URL: https:/www.informio.ru/update/ wuz/41869 (дата обращения: 11.11.2021).

4. Муравьев И.А. О конституционном праве на образование и проблемах его реализации // Юридическая наука: история и современность. 2018. № 11. - С. 45-49.

5. Открытое образование. - URL: https://openedu.ru (дата обращения: 11.11.2021). 
6. Приказ Министерства образования и науки Российской Федерации от 23 августа 2017 г. № 816 «Об утверждении Порядка применения организациями, осуществляющими образовательную деятельность, электронного обучения, дистанционных образовательных технологий при реализации образовательных программ» // Официальный интернет-портал правовой информации (www.pravo.gov.ru). 2017. 20 сентября. № 0001201709200016.

7. Федеральное агентство по делам Содружества Независимых Государств, соотечественников, проживающих за рубежом, и по международному гуманитарному сотрудничеству (Россотрудничество). - URL: https://rwp. agency (дата обращения: 11.11.2021).

8. Федеральный закон от 29 декабря 2012 года № 273-Ф3 «Об образовании в Российской Федерации» (ред. от 02.07.2021) // Российская газета. 2012. 31 декабря.

9. Щукина Т.В. Партнерство университетов в Российской Федерации: правовое регулирование, типология и вызовы времени // Вопросы экономики и права. 2020. № 150. - С. 38-43.

10. ЮНЕСКО принимает первый международный договор ООН о высшем образовании. - URL: https://ru.unesco. org/news/yunesko-prinimaet-pervyy-mezhdunarodnyy-dogovor-oon-o-vysshem-obrazovanii (дата обращения: 11.11.2021).

11. Mitchell N. EU action plan for digital skills for all broadly welcomed. - URL: https://www.universityworldnews. com/post.php?story=20201003010729135 (дата обращения: 11.11.2021).

12. Ross J. Australia pioneers 'stacking' of microcredentials into degrees. - URL: https://www.timeshighereducation. com/news/australia-pioneers-stacking-microcredentials-degrees (дата обращения: 11.11.2021).

13. Sharma Y. Offshore learning hubs keep overseas students engaged. - URL: https://www.universityworldnews. com/post.php?story=20210924100159154 (дата обращения: 11.11.2021).

14. Walbank J. New UCQOL platform launched to assist UAE universities. - URL: https://www.globaleducationtimes. org/news/asia/new-ucqol-platform-launched-to-assist-uae-universities/1961/ (дата обращения: 11.11.2021). 